\section{Vitamin C Supplements and Diabetic Cutaneous Capillary Fragility}

Cutaneous capillary strength was investigated in 12 diabetics, six of whom had symptomatic retinopathy (age range 25-71 years) and 24 controls (age range 21-61 years). The effect on the diabetics of a dietary supplement of vitamin $\mathrm{C}$ was studied.

\section{Methods and Results}

Cutaneous capillary fragility was measured using apparatus described by Hart and Cohen. ${ }^{1}$ We modified the procedure by applying a much lower negative pressure to the anterior forearm surface $(100 \mathrm{~mm} \mathrm{Hg}$ instead of $375 \mathrm{~mm} \mathrm{Hg}$ ) and increasing this by $50 \mathrm{~mm} \mathrm{Hg}$ every minute to a maximum of $300 \mathrm{~mm} \mathrm{Hg}$ while recording the petechiae observed. The retinae were examined and blood was taken for vitamin $\mathrm{C}$ and other assays (to be reported elsewhere). Dietary vitamin $C$ intake was assessed over one week and in half the diabetics and a quarter of the non-diabetics the intake was less than the recommended $315 \mathrm{mg} /$ week. $^{2}$

The 12 diabetics were divided randomly into two groups. Group 1 was given placebo for one month followed by vitamin $\mathrm{C}(1 \mathrm{~g} /$ day) for two months. Group 2 was given vitamin $\mathrm{C}$ supplements for two months and then placebo for one month. Each month cutaneous capillary fragility was assessed, blood vitamin $\mathrm{C}$ estimated, and the fundi examined.

In all subjects an increase of negative pressure led to a logarithmic increase in the number of petechiae observed. The diabetics showed petechiae at much lower negative pressures than the controls and all diabetics with retinopathy had very fragile capillaries. In group 1 cutaneous capillary fragility did not change after placebo treatment, but the capillary strength in all diabetics (in both groups) improved during vitamin $\mathrm{C}$ treatment. In group 2 the capillary strength of four of the six diabetics deteriorated at the end of the final month on placebo treatment. No retinal changes were observed during vitamin $\mathrm{C}$ treatment.

\section{Discussion}

Our technique provided a simple measurement of capillary fragility. The results at the initial assessment confirmed the findings of Hunte et al. ${ }^{3}$ that diabetics, particularly those with complications, have more fragile skin capillaries than normal (see fig.). Though many diabetics had low vitamin $C$ intakes capillary fragility was not related to vitamin $\mathrm{C}$ intake in the group as a whole. Furthermore, since diabetics with an intake above the recommended $45 \mathrm{mg} /$ day had fragile capillaries and daily $1 \mathrm{~g}$ supplements brought their capillary strength towards normal, diabetics probably need more vitamin $C$ than normal people (the effects of vitamin $C$ supplements were not maintained after withdrawal of treatment).

Studies of the effect of insulin on the exchange of vitamin $\mathrm{C}$ in the peripheral tissues indicated that the response (and thus possibly the tissue distribution of the vitamin) differed in diabetics and normal people, though glucose uptake and plasma vitamin $C$ levels were similar. ${ }^{4}$

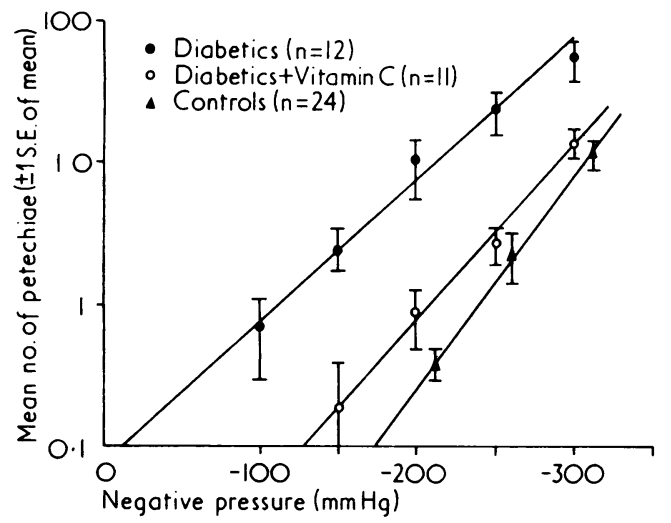

Effect of various negative pressures on mean number of petechiae seen in diabetics before and after vitamin $C$ supplements and in a group of nondiabetics.
Can high vitamin $\mathrm{C}$ intakes of up to $7000 \mathrm{mg} /$ week prevent retinopathy as well as protecting skin capillary strength? The retina normally has a very high concentration of ascorbic acid but we do not know whether raising the circulating levels of vitamin $\mathrm{C}$ can overcome any impaired ability to concentrate the vitamin in the retina. Nevertheless, there were no retinal changes during vitamin treatment, but in one of the diabetics a fresh crop of small red dots, taken to be retinal haemorrhages, occurred after withdrawal. Possibly a sudden reduction of vitamin $\mathrm{C}$ intake, which may lead to a dramatic fall in plasma and tissue levels, ${ }^{5}$ may also cause adverse local effects in diabetics.

1 Hart, A., and Cohen, H., British Medical fournal, 1969, 2, 89.

2 Harper, A. E., Annals of the New York Academy of Sciences, Second Conference on Vitamin $C, 1974$, in press.

${ }^{3}$ Hunter, P. R., et al., Diabetologia, 1971, 7, 20.

4 Cox, B. D., et al., Clinical Science and Molecular Medicine, 1974, 47, 63.

5 Spero, A. L., Annals of the New York Academy of Sciences, Second Conference on Vitamin $C, 1974$, in press.

Department of Medicine, Guy's Hospital, London SE1 9RT

BRIAN D. COX, B.SC., PH.D., Lecturer

Derby Royal Infirmary, Derby

W. J. H. BUTTERFIELD, M.D., F.R.C.P., Honorary Consultant

\section{Anaphylactic Reactions after Use of CT I34I (Althesin)}

CT 1341 (Althesin) is a mixture of two steroids, alphaxalone and alphadolone acetate, dissolved in $0.25 \%$ saline with $20 \%$ polyoxyethylated castor oil (Cremophor EL). These steroids are weakly antioestrogenic with no other steroid properties. CT 1341 is a rapid and short-acting anaesthetic induction agent, producing less cardiovascular and respiratory depression than barbiturates and no "hangover."

At Good Hope General Hospital CT 1341 was used for two years in 3500 anaesthetics; four patients with no history of allergy suffered severe hypersensitivity reactions.

\section{Case Reports}

Case 1.-A healthy 17-year-old boy had a fractured tibia reduced under general anaesthesia using intravenous CT $13415 \mathrm{ml}$, suxamethonium $75 \mathrm{mg}$ and endotracheal intubation and maintained with nitrous oxide, oxygen, and halothane. No problems occurred. Eleven days later the same anaesthetic technique was used for remanipulation. He developed bronchospasm, tachycardia ( 180 beats/min), and hypotension (systolic blood pressure $<90 \mathrm{~mm} \mathrm{Hg}$ ). Hydrocortisone $500 \mathrm{mg}$, aminophylline $250 \mathrm{mg}$, and $\mathrm{Har}-$ man's solution $500 \mathrm{ml}$ were given intravenously. The bronchospasm responded rapidly, but hypotension persisted for five hours. Skin tests ${ }^{1}$ to both CT 1341 and suxamethonium gave negative results.

Case 2.-A healthy 44-year-old woman was admitted for skin grafting. Anaesthesia was induced intravenously with althesin $7 \mathrm{ml}$, suxamethonium $50 \mathrm{mg}$, and endotracheal intubation and maintained with nitrous oxide, oxygen, and halothane. Diazepam $10 \mathrm{mg}$ was also given. A month later the same anaesthetic technique was used again but with CT $13416 \mathrm{ml}$ and diazepam $5 \mathrm{mg}$. After intubation she developed tachycardia $(>100$ beats $\mathrm{min}$ ), bronchospasm, cyanosis, generalized urticaria, and severe hypotension. Her condition improved after ventilation with oxygen and intravenous hydrocortisone $600 \mathrm{mg}$ and dextran $70500 \mathrm{ml}$. Hypotension lasted for one hour. Skin tests ${ }^{1}$ produced positive results to CT 1341 and propanidid but not to suxamethonium and diazepam.

Case 3.- A healthy 19-year-old man had a fractured ankle reduced under general anaesthesia using CT $13415 \mathrm{ml}$ intravenously with no ill effects. Thirteen days later the same technique was used for remanipulation, but he started to cough and developed a deep flush all over his body before all the CT 1341 had been given. He was intubated, using suxamethonium $100 \mathrm{mg}$, but became pale and pulseless. After inflation with oxygen he had a tachycardia $(>180$ beats/min), remained hypotensive (systolic blood pressure $<70 \mathrm{~mm} \mathrm{Hg}$ ), and had a rash. Hydrocortisone $500 \mathrm{mg}$ and chlorpheniramine $10 \mathrm{mg}$ were given intravenously and Dextran 70 (in saline) $500 \mathrm{ml}$ infused rapidly intravenously. He recovered but was hypotensive for one and a half 